Peter Salzer · Nadja Feddermann · Andres Wiemken

Thomas Boller · Christian Staehelin

\title{
Sinorhizobium meliloti-induced chitinase gene expression in Medicago truncatula ecotype R108-1: a comparison between symbiosis-specific class V and defence-related class IV chitinases
}

Received: 6 December 2003 / Accepted: 6 March 2004/Published online: 24 April 2004

(C) Springer-Verlag 2004

\begin{abstract}
The Medicago truncatula (Gaertn.) ecotypes Jemalong A17 and R108-1 differ in Sinorhizobium meliloti-induced chitinase gene expression. The pathogen-inducible class IV chitinase gene, Mtchit 4, was strongly induced during nodule formation of the ecotype Jemalong A17 with the $S$. meliloti wild-type strain 1021. In the ecotype R108-1, the S. meliloti wild types Sm1021 and Sm41 did not induce Mtchit 4 expression. On the other hand, expression of the putative class $\mathrm{V}$ chitinase gene, Mtchit 5, was found in roots of $M$. truncatula $\mathrm{cv}$. R108-1 nodulated with either of the rhizobial strains. Mtchit 5 expression was specific for interactions with rhizobia. It was not induced in response to fungal pathogen attack, and not induced in roots colonized with arbuscular mycorrhizal (AM) fungi. Elevated Mtchit 5 gene expression was first detectable in roots forming nodule primordia. In contrast to Mtchit 4, expression of Mtchit 5 was stimulated by purified Nod factors. Conversely, Mtchit 4 expression was strongly elevated in nodules formed with the K-antigen-deficient mutant PP699. Expression levels of Mtchit 5 were similarly increased in nodules formed with PP699 and its parental wild-type strain Sm41. Phylogenetic analysis of the deduced amino acid sequences of Mtchit 5 (calculated molecular weight $=$ 41,810 Da, isoelectric point $\mathrm{pH} 7.7$ ) and Mtchit 4 (calculated molecular weight $30,527 \mathrm{Da}$, isoelectric
\end{abstract}

P. Salzer $(\bowtie) \cdot$ N. Feddermann $\cdot$ A. Wiemken $\cdot$ T. Boller C. Staehelin

Botanisches Institut der Universität Basel,

Hebelstrasse 1, 4056 Basel, Switzerland

E-mail: Peter.Salzer@unibas.ch

Tel.: + 41-61-2672318

Fax: +41-61-2672330

Present address: C. Staehelin

Sciences III, Université de Genève,

30 Quai Ernest-Ansermet,

1211 Genève 4, Switzerland point $\mathrm{pH}$ 4.9) revealed that the putative Mtchit 5 chitinase forms a separate clade within class $\mathrm{V}$ chitinases of plants, whereas the Mtchit 4 chitinase clusters with pathogen-induced class IV chitinases from other plants. These findings demonstrate that: (i) Rhizobium-induced chitinase gene expression in M. truncatula occurs in a plant ecotype-specific manner, (ii) Mtchit 5 is a putative chitinase gene that is specifically induced by rhizobia, and (iii) rhizobia-specific and defence-related chitinase genes are differentially influenced by rhizobial Nod factors and $\mathrm{K}$ antigens.

Keywords Class IV and V chitinase $\cdot \mathrm{K}$ antigen Medicago truncatula ecotypes R108-1 and Jemalong A17 $\cdot$ Nod factors $\cdot$ Sinorhizobium $\cdot$ Suppression of plant defence

Abbreviations AM: Arbuscular mycorrhiza(l) · BAC: Bacterial artificial chromosome - bp: Base pairs · RT-PCR: Polymerase chain reaction after reverse transcription

\section{Introduction}

Under conditions of nitrogen limitation, legumes establish a symbiosis with nitrogen-fixing soil bacteria belonging to the family of Rhizobiaceae. Once the rhizobia have entered the root hairs, infection threads are formed, and some cortical root cells become meristematic resulting in the development of a highly specialized symbiotic organ, the nodule. Formation of nodules is the result of a molecular dialogue between rhizobia and the host plant. The plants secrete flavonoids into the rhizosphere, where they stimulate the rhizobia to synthesize Nod factors (lipo-chitooligosaccharide signal molecules). The Nod factors induce various responses in the host plant, including root hair deformation and cortical cell division (Perret et al. 2000). In addition to Nod factors, specific rhizobial surface compounds, exopolysaccharides (EPS), 
lipopolysaccharides (LPS), cyclic $\beta$-glucans and $\mathrm{K}$ antigens (also named capsular polysaccharides) are required for establishing a symbiosis. Increasing data suggest that certain forms of surface polysaccharides interact with components of the host plant at different stages of the symbiosis (e.g. Pellock et al. 2000), thereby avoiding or suppressing inducible plant defence reactions (Niehaus et al. 1993; Albus et al. 2001; Mithöfer et al. 2002). Whether $\mathrm{K}$ antigens have an effect on genes induced during nodulation has not been studied yet. K antigens of Sinorhizobium meliloti are analogous to the group II $\mathrm{K}$ antigens of Escherichia coli. They adhere tightly to the cell surface of the rhizobia and usually contain a high proportion of Kdo (3-deoxy-D-manno-2-octulosonic acid; Petrovics et al. 1993; Reuhs et al. 1993; Kannenberg et al. 1998).

Nodulins are plant proteins that are specifically induced during the life cycle of a nodule. According to the timing of their synthesis during nodule development, they are divided into early and late nodulins. Early nodulins are synthesized during root hair deformation, infection thread formation and nodule morphogenesis. Late nodulins appear first in nodules after bacterial endocytosis. Most early nodulins seem to be involved in symbiosis-related alterations of the plant cell wall. Some of them exhibit similarities to pathogenesis-related proteins (Gamas et al. 1998; Goormachtig et al. 1998). A number of nodulins are also expressed in roots colonized by mycorrhizal fungi (Wyss et al. 1990; Hirsch and Kapulnik 1998), indicating a common role in arbuscular mycorrhizal (AM) and rhizobial symbiosis. For instance, Medicago truncatula transformants constitutively expressing the enod40 gene exhibited an accelerated development of nodules (Charon et al. 1999) and also an increased colonization with AM fungi (Staehelin et al. 2001).

Chitinases are frequently regarded as pathogenesisrelated proteins. They hydrolyse chitin (poly $\beta-1,4-N$ acetylglucosamine), which is a major component of most higher fungi and arthropods. Usually, plants possess a set of different chitinases, which belong to the glycosyl hydrolase families 18 or 19 and are subdivided into different classes (Melchers et al. 1994; Neuhaus et al. 1996; Hamel et al. 1997). Synthesis of chitinases is often induced in response to pathogen attack. Chitinases have antifungal activity, particularly in combination with $\beta$-1,3-glucanase (e.g. Mauch et al. 1988). When overexpressed in transgenic plants, certain chitinases enhance resistance against fungal pathogen attack (e.g. Broglie et al. 1991). Some chitinases also display lysozyme activity and hydrolyse $\beta$-1,4-linkages between $N$-acetylmuramic acid and $N$-acetylglucosamine in peptidoglycanes of bacterial cell walls (e.g. Brunner et al. 1998).

Apart from their role in pathogen defence, chitinases also have a role in symbiotic interactions. However, their function in symbioses is less well understood. Certain chitinase isoenzymes are specifically induced in soybean nodules (Staehelin et al. 1992;
Xie et al. 1999) and near aborted infection threads in the interaction between alfalfa and Sinorhizobium meliloti (Vasse et al. 1993). In Sesbania rostrata plants, a chitinase (Goormachtig et al. 1998) and a chitinaserelated gene (Goormachtig et al. 2001) are strongly induced during the early stages of stem nodule development. Chitinases of legumes have received particular attention because certain rhizobial Nod factors are substrates for chitinases (reviewed by Perret et al. 2000). The degradation products formed are only weakly active on their respective host plants (Heidstra et al. 1994; Staehelin et al. 1994). Thus, it has been proposed that cleavage of Nod factors is necessary to limit the amount of active Nod factors after their perception by the host plant (Staehelin et al. 1995; Goormachtig et al. 1998). Chitinases can also be directly involved in processes related to plant development by modifying extracellular $N$-acetylglucosaminecontaining arabinogalactan proteins (De Jong et al. 1992; van Hengel et al. 2001). In addition to these enzymatically active chitinases, a putative receptor kinase with a $\mathrm{C}$-terminal class $\mathrm{V}$ chitinase domain (Kim et al. 2000) and chitinase homologs without catalytic activity have been identified (Perlick et al. 1996; Goormachtig et al. 2001).

Medicago truncatula $(=$ barrel medic) is widely used as a model plant that allows studies on symbiotic plant-microbe interactions (Cook et al. 1997). $M$. truncatula exists in many ecotypes. The ecotype Jemalong was selected for the ongoing American and European $M$. truncatula genome sequencing and gene expression projects (van den Bosch and Stacey 2003). The ecotype R108-1 is known for its superior in vitro regeneration and transformation properties (Hoffmann et al. 1997). In our previous work we isolated partial chitinase DNA sequences from an $M$. truncatula bacterial artificial chromosome (BAC) library and determined transcript levels by semi-quantitative reverse transcription-polymerase chain reaction (RT-PCR) in various pathogenic and symbiotic interactions (Salzer et al. 2000). Transcripts of the class IV chitinase gene, Mtchit 4, continuously accumulated in the interaction of M. truncatula Jemalong A17 with S. meliloti 1021. In our previous work (Salzer et al. 2000), however, we were not able to identify a chitinase gene that is specifically induced during interactions with $S$. meliloti. In order to learn more about chitinase gene expression during nodule formation and about the effects of rhizobial signal molecules, we extended our studies on the $M$. truncatula ecotype R108-1. The comparison of chitinase gene expression patterns between the ecotypes Jemalong A17 and R108-1 drew our attention to the class IV chitinase gene, Mtchit 4, and the class $\mathrm{V}$ chitinase gene, Mtchit 5 . In this work we present a comparative, real-time RT-PCR-based investigation of Mtchit 4 and Mtchit 5 gene expression and introduce Mtchit 5 as a new rhizobia-specific induced gene that is inversely influenced by Nod factors and $\mathrm{K}$ antigen compared to the defence-related Mtchit 4 gene. 


\section{Materials and methods}

Treatments and culture of plants, bacteria, and fungi

Medicago truncatula (Gaertn.) ecotype R108-1 was kindly provided by E. Kondorosi (CNRS, Gif-surYvette, France), ecotype Jemalong A17 by T. Huguet (CNRS-INRA Castanet-Tolosan, France). Seeds were freshly released from seed pods, treated with concentrated sulphuric acid for $4 \mathrm{~min}$, rinsed 8 to 10 times with autoclaved water and germinated in Petri dishes containing $1 \%$ water agar. Germination and growth occurred in a Sanyo Versatile Environmental Test Chamber (Sanyo Electric, Japan) with 18-h day $\left(140 \mu \mathrm{mol}\right.$ photons $\left.\mathrm{m}^{-2} \mathrm{~s}^{-1}, 2^{\circ} \mathrm{C}\right), 6-\mathrm{h}\left(18^{\circ} \mathrm{C}\right)$ night cycles. When used for spraying experiments, seeds were germinated in vertical orientation with roots shaded by aluminium foil. For all other experiments, seeds were germinated in horizontal orientation and planted into Magenta jars containing Terra Green (Oil Dri type III R; Lobbe Umwelttechnik, Iserlohn, Germany) after the primary leaves had started to expand. B\&D nutrient solution (Broughton and John 1979) with $2 \mathrm{mM}$

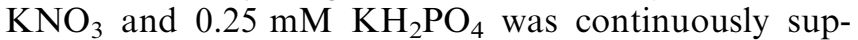
plied from a reservoir, which was connected by a wick with the Terra Green.

The following Sinorhizobium meliloti strains and mutants were used in this work: S. meliloti 1021 wild type; S. meliloti $\mathrm{Sm} 41$ wild type and its K-antigen-deficient derivative PP699, which is mutated in the rkp- 1 (formerly fix-23) region (Putnoky et al. 1990; Petrovics et al. 1993; Kiss et al. 1997); AK631lpsZ::Tn5 with a mutated lpsZ gene (Reuhs et al. 1995); and PP666h, which is AK631 mutated in the rkp-l (formerly fix-23) region (Putnoky et al. 1990). The bacteria were grown in GTS medium (Kiss et al. 1979) on a rotatory shaker $(150 \mathrm{rpm})$ at $27^{\circ} \mathrm{C}$. For inoculation, $1 \mathrm{ml}$ of the bacterial solution $\left(\mathrm{OD}_{600}\right.$ about 1.0) was either sprayed directly on the roots or pipetted to the rhizosphere. In control experiments, $1 \mathrm{ml}$ GTS medium was applied. The plant material was harvested after the indicated times, frozen in liquid nitrogen and stored at $-80^{\circ} \mathrm{C}$ until extraction of RNA.

Nod factors were purified from $S$. meliloti strain 1021(pEK327) (Schultze et al. 1992). Supernatants of bacterial cultures were extracted with $n$-butanol and fractionated by reverse-phase HPLC (Waters C18 column), using $35 \%$ acetonitrile/water, $40 \mathrm{mM}$ ammonium acetate as the mobile phase. The fractions containing NodSm-IV $\left(\mathrm{C}_{16: 2}, \mathrm{~S}\right)$ were collected and desalted as described by Staehelin et al. (2000). For treatment of roots, $1 \mathrm{ml}$ of $0.5 \mathrm{mM} \operatorname{NodSm}-\operatorname{IV}\left(\mathrm{C}_{16: 2}, \mathrm{~S}\right)$, was sprayed on vertically grown roots of young plants, which had reached the stage of expanded cotyledons. In control experiments, $1 \mathrm{ml}$ water was sprayed.

Culture and inoculation with the AM fungus Glomus intraradices was performed as previously described (Salzer et al. 2000) with about 400 spores, which had been isolated from Daucus carota/Glomus intraradices in vitro cultures (Bécard and Fortin 1988). In control experiments, an equivalent amount of water was added. The degree of mycorrhization was determined by the gridline intersection method (Giovanetti and Mosse 1980).

Culture and inoculation with Fusarium solani f. sp. phaseoli strain W-8 (kindly provided by the Novartis fungal pathogen collection) was performed as previously described (Salzer et al. 2000). For mock inoculation, V8 agar plugs were placed on the root surface.

\section{Cloning, sequencing and sequence analysis}

Cloning and sequencing of Mtchit 5 An adapter-ligated library was constructed with the Universal Genome Walker kit (Clontech, Palo Alto, CA, USA) and the Expand Long Template PCR System (Roche Diagnostics, Mannheim, Germany). To this purpose, genomic DNA was isolated from roots of axenically grown $M$. truncatula R108-1 plants using the Nucleon Phyto Pure DNA extraction kit (Amersham Biosciences) followed by three extractions with phenol: chloroform (1:1). Aliquots of the purified DNA were digested with $D r a \mathrm{I}, E c o$ RV, PvuII or StuI and adapters were ligated to both blunt cut ends of the obtained DNA fragments according to the protocol of the Genome Walker kit. First PCR was performed with an aliquot of the adapter-ligated DNA fragments with the adapter-specific primers, Adaptor 1 (Genome Walker kit) and Mtchit 5-specific primers GSP1 or GSP3 (Table 1) followed by a second, nested PCR with 1:1,000-diluted aliquots of the first PCR using the nested adapter-specific primers, Adaptor 2 (Genome Walker kit) and nested Mtchit 5-specific primers GSP2 and GSP4 (Table 1). PCR was performed with the Long Template PCR System according to the manufacturer's recommendations (Roche Diagnostics) using buffer 3 . Thermal cycling was performed with a Techne Progene cycler (Techne, Duxford, Cambridge, UK). The cycling program for both PCRs was 1 cycle: $2 \mathrm{~min}$ at $92^{\circ} \mathrm{C}, 10$ cycles: $10 \mathrm{~s}$ at $92^{\circ} \mathrm{C}, 30 \mathrm{~s}$ at $60^{\circ} \mathrm{C}$ and $90 \mathrm{~s}$ at $68^{\circ} \mathrm{C}, 20$ cycles: $10 \mathrm{~s}$ at $92^{\circ} \mathrm{C}, 30 \mathrm{~s}$ at $60^{\circ} \mathrm{C}$, and $90 \mathrm{~s}$ at $68^{\circ} \mathrm{C}$ with an increased extension per cycle of $20 \mathrm{~s}$ at $68^{\circ} \mathrm{C}$. PCR products obtained after the second PCR were purified with the High Pure PCR purification kit (Roche Diagnostics) and cloned into pGEMTeasy using the pGEMTeasy Vector System (Promega, Madison, WI, USA). DNA sequencing was performed with the ABI Prism Big Dye Terminator Sequencing Reaction kit and an ABI 310 sequencer following the manufacturer's recommendations (Applied Biosystems, Foster City, CA, USA). The sequences obtained from the adapter-ligated library were assembled and primers were designed (Mtchit5 start-f, Mtchit5 stop-b) that covered the $5^{\prime}$ and $3^{\prime}$ ends of the assembled sequences. The primers used for cloning and sequencing reactions in forward and backward direction are listed in Table 1. 
Table 1 Primers used for construction of the adaptor-ligated library, cloning and sequencing of Mtchit 5 and Mtchit 4, and primers used for real-time PCR. The following primers have already been described elsewhere: Adaptor primer 1, and nested adaptor primer 2 (Universal Genome Walker kit user manual,
Clontech, http://www.clontech.com), sequencing primers M13 forward and M13 backward (pGEM-T and pGEM-Teasy Vector Systems, http://www.promega.com), Mtchit 3-3f, Mtchit 3-3b, Mtubi-f, Mtubi-b (Salzer et al. 2000). Tm Annealing temperature

\begin{tabular}{|c|c|c|c|}
\hline Name & $\operatorname{Tm}\left({ }^{\circ} \mathrm{C}\right)$ & Sequence & Comment \\
\hline GSP1 & 67.1 & CCGATCCGGTCTCCTTGTCATACACC & $\begin{array}{l}\text { Cloning primers } \\
\text { Gene-specific } M \text { tchit } \\
5 \text { forward, first PCR }\end{array}$ \\
\hline GSP2 & 67.2 & CCCGATTCCATGCACATTCGGATCCTG & $\begin{array}{l}\text { Gene-specific } \text { Mtchit } \\
5 \text { forward, nested PCR }\end{array}$ \\
\hline GSP3 & 67.1 & CAGGATCCGAATGTGCATGGAATCGGG & $\begin{array}{l}\text { Gene-specific Mtchit } \\
5 \text { backward, first PCR }\end{array}$ \\
\hline $\begin{array}{l}\text { Mtchit } 5 \\
\text { start-f }\end{array}$ & 63.1 & GTGACATGCCACTTAAGAATGTTGAACAC & $\begin{array}{l}5^{\prime} \text { end of Mtchit } 5 \text {, full-length } \\
\text { clone forward }\end{array}$ \\
\hline $\begin{array}{l}\text { Mtchit5 } \\
\text { stop-b }\end{array}$ & 63.8 & GTCACAAATTATCACACACTTGGTTTGTAAACC & $\begin{array}{l}\text { 3' end of Mtchit 5, full-length } \\
\text { clone backward }\end{array}$ \\
\hline $\begin{array}{l}\text { Mtchit4 } \\
\text { start-f }\end{array}$ & 67.7 & $\begin{array}{l}\text { ATGACTATGATGGGAAACAAATCACT } \\
\text { AAGCATATGTATG }\end{array}$ & $\begin{array}{l}5^{\prime} \text { end of Mtchit } 4 \text {, full-length } \\
\text { clone forward }\end{array}$ \\
\hline Dra I-specific 2 & 65.3 & GCCTTTCACACGTGTAGTTGATGATGGTG & $\begin{array}{l}\text { For internal regions of Dra I fragment, } \\
\text { backward }\end{array}$ \\
\hline Mtchit4 seq1 & 64.4 & GCTAATGTGGCTGACATCCTTACACAAG & For internal regions Mtchit 4 , forward \\
\hline Mtchit4 seq1b & 64.4 & CTTGTGTAAGGATGTCAGCCACATTAGC & For internal regions Mtchit 4, backward \\
\hline Mtchit4 seq2 & 64.2 & GAACTACAACTATGGACCAGCTGGAAG & For internal regions Mtchit 4, forward \\
\hline Mtchit4 seq2b & 64.2 & CTTCCAGCTGGTCCATAGTTGTAGTTC & $\begin{array}{l}\text { For internal regions Mtchit } 4 \text {, backward } \\
\text { Primers for real-time PCR }\end{array}$ \\
\hline Chit5 rt-f & 59.0 & GGGTTGATGGTGGAATGGCG & Gene-specific Mtchit 5, forward \\
\hline Chit5 rt-b & 60.5 & GATCCGGTCTCCTTGTCATAC & Gene-specific Mtchit 5, backward \\
\hline Chit4 rt-f & 66.6 & GGTGATGCATATTGTGGCACAGGG & Gene-specific Mtchit 4, forward \\
\hline Chit4 rt-b & 67.4 & GCAGCAGCAACCTCACGTTTGGAG & Gene-specific Mtchit 4, backward \\
\hline
\end{tabular}

Cloning and sequencing of Mtchit 4 A database comparison in TIGR (http://www.tigr.org/tdb/tgi/mtgi/) with the partial Mtchit 4 sequence (accession number AF167328) obtained from the M. truncatula Jemalong A17 BAC clone 46B22 (Salzer et al. 2000) resulted in a $100 \%$ match with the tentative class IV chitinase consensus sequence TC60709. Primers Mtchit4 start-f and Mtchit4 stop-b comprising the start and the stop codon of TC60709 were designed (Table 1). Using the Expand PCR System, Mtchit 4 was synthesized using genomic DNA from M. truncatula cv. R108-1 as template, cloned into pGEMTeasy, and sequenced.

Sequence analysis Sequences were analysed using EditView 1.0 (Perkin Elmer). Sequence alignments (BestFit, PileUp), translation of the nucleotide acid sequences (Translate), database searches (BLASTP, BLASTN), determination of the molecular weight (Map) and isoelectric point (Isoelectric), analysis of known protein motives (HmmerPfam), and analysis of signal peptide (SPScan) were performed with the Accelrys SeqWeb Version 2.1 Web-based Sequence Analysis. In an alternative approach, analysis of signal peptides was also performed with PSORT (old version for bacterial/plant sequences, http://psort.nibb.ac.jp/ form.html). For phylogenetic analysis, deduced amino acid sequences were aligned with Clustal $\mathrm{W}$ and distance matrices were calculated (http://www.mbio.ncsu.edu/Bioedit/bioedit.html). Unrooted phylogenetic trees were constructed with Phylip version 3.6 (http:// evolution.genetics.washington.edu/phylip.html) applying the Neighbor-Joining method 3.6a3. All other molecular techniques were performed according to Sambrook et al. (1989).

Semi quantitative and quantitative RT-PCR

Semi quantitative RT-PCR was performed entirely as previously described (Salzer et al. 2000), except that 31 PCR cycles were performed.

For real-time RT-PCR, RNA was isolated from roots, leaves and flowers of $M$. truncatula R108-1, treated with DNAse I and reverse-transcribed as previously described (Salzer et al. 2000), except that 10 units RNase-free DNase I and reaction buffer from MBI Fermentas (Vilnius, Lithunia) were used. 
Real-time PCR was performed with a Gene Amp 5700 Sequence Detection System (Applied Biosystems) with the default thermal cycling program for Sybr Green analysis. The thermal profile was, 1 cycle: $50^{\circ} \mathrm{C}$, 2 min, 1 cycle: $95^{\circ} \mathrm{C}, 10 \mathrm{~min}, 40$ cycles: $95^{\circ} \mathrm{C}, 15 \mathrm{~s}$, $60^{\circ} \mathrm{C}, 1 \mathrm{~min}$. A $25-\mu \mathrm{l}$ reaction volume consisted of $1 \mu \mathrm{l}$ of cDNA, $12.5 \mu \mathrm{l}$ Sybr Green PCR $2 \times$ reaction mix, $5.5 \mu \mathrm{l}$ water, $3 \mu \mathrm{l}$ of $2 \mu \mathrm{M}$ gene-specific forward primers, and $3 \mu \mathrm{l}$ of $2 \mu \mathrm{M}$ gene-specific backward primers (Table 1). Gene-specific primers for Mtchit 5, and Mtchit 4 were designed based on sequence information of the full-length coding region. Gene specificity of the primers was controlled by comparison in pairs (BestFit) with partial chitinase sequences of Mtchit 1, Mtchit 2, and Mtchit 3-2 (Salzer et al. 2000), and full-length sequences of Mtchit 3-3 (AY238969), Mtchit 3-4 (AY238970), and Mtchit 3-1 (AY294484). Calibration was performed with a dilution series of $6.4 \mathrm{ng}, 3.2 \mathrm{ng}, 1.6 \mathrm{ng}, 0.8 \mathrm{ng}$ and $0.4 \mathrm{ng}$ genomic DNA from $M$. truncatula cv. R108-1 corresponding to $22,122,13,061,6,530,3,265$, and 1,632 copies of Mtchit 5, Mtchit 4 and ubiquitin. Copy numbers were calculated based on a haploid genome weight of $0.49 \mathrm{pg}$ (Blondon et al. 1994) under the assumption of Mtchit 5 and Mtchit 4 being singlecopy genes (Salzer et al. 2000). DNA was isolated from axenically grown seedlings with DNeasy (Qiagen) and subsequently treated with RNase following the manufacturer's instructions. Ubiquitin (ubi) was measured as internal standard using an $M$. truncatulaspecific primer combination (Salzer et al. 2000). For calculation of copy numbers from amplification plots, a threshold of 0.1 was used. All samples were measured in triplicate. Standardized expression levels are given as Mtchit/ubi ratios. They were calculated from the average copy numbers of the chitinase and the $M$. truncatula-specific ubiquitin transcripts.

Fig. 1 Differential expression of chitinase genes in various Medicago truncatula ecotypes. The plants were inoculated with the Sinorhizobium meliloti wild-type strains 1021 or Sm41, or were mock-inoculated with GTS medium (no rhizobia). RNA was isolated from nodulated roots 5 weeks post inoculation. cDNA obtained by reverse transcription has been diluted 1:1, 1:4, 1:16, and 1:64 and was subsequently subjected to 31 PCR cycles. The picture shows the ethidium bromide-stained PCR products. Strong expression of Mtchit 4 is apparent in the ecotype Jemalong A17. Expression of Mtchit 5 is obvious in the ecotype R108-1 but hardly detectable in the ecotype Jemalong A17. M. truncatula-specific ubiquitin (Mtubi) served as cDNA loading control. The picture shows the result, as it was obtained in two independent experiments

\section{Results}

Differential expression of chitinase genes in the M. truncatula ecotypes Jemalong A17 and R108-1

To extend our knowledge about chitinase gene expression in the model legume $M$. truncatula, we compared the expression patterns of Mtchit 1, Mtchit 2, Mtchit 3-1, Mtchit 3-2, Mtchit 3-3, Mtchit 3-4, Mtchit 4, and Mtchit 5 (Salzer et al. 2000) between the ecotypes Jemalong A17 and R108-1. Applying conventional semi-quantitative RT-PCR for these eight genes, we found two remarkable differences between chitinase gene expression in nodulated roots of the two M. truncatula ecotypes. (i) Mtchit 4 transcripts, which continuously accumulated during nodule formation of S. meliloti 1021 on the ecotype Jemalong A17 (Salzer et al. 2000), was not elevated above its basic expression level in nodules formed with the $S$. meliloti wild-type strains 1021 and Sm41 in the ecotype R108-1 (Fig. 1). (ii) Mtchit 5 expression, which was previously not detected in roots of M. truncatula cv. Jemalong A17 nodulated with S. meliloti Sm1021 (Salzer et al. 2000), could be detected in roots of the ecotype R108-1 that were nodulated with 1021 or Sm41 (Fig. 1). By performing a higher number of PCR cycles, 31 instead of 28 (Salzer et al. 2000), Mtchit 5 expression could also be observed in nodulated roots of M. truncatula Jemalong A17. However, the signal was so weak, that it could hardly be seen (Fig. 1).

\section{Cloning and sequencing of Mtchit 4}

A database search in the TIGR M. truncatula database (http://www.tigr.org/tdb/tgi/mtgi/) resulted in a $100 \%$ match between the partial Mtchit 4 sequence (AF167328, Salzer et al. 2000) and the tentative consensus sequence TC60709 of M. truncatula cv. Jemalong A17. Primers "Mtchit4 start-f" beginning with the start codon and "Mtchit4 stop-b" beginning with the stop codon of TC60709 were designed (Table 1) and used for PCR with genomic DNA of M. truncatula cv. R108-1. A single 1,245-bp PCR product was obtained comprising the full-length coding region of Mtchit 4. The coding region was interrupted by a 396-bp intron located at the conserved position of introns of class IV chitinase genes in angiosperms (Wiweger et al. 2003). Sequence data of Mtchit 4 are deposited at GenBank and are accessible under AY490790. Sequence comparison between putative Mtchit 4 and TC60709 gene products revealed $>98 \%$ identity. The putative gene
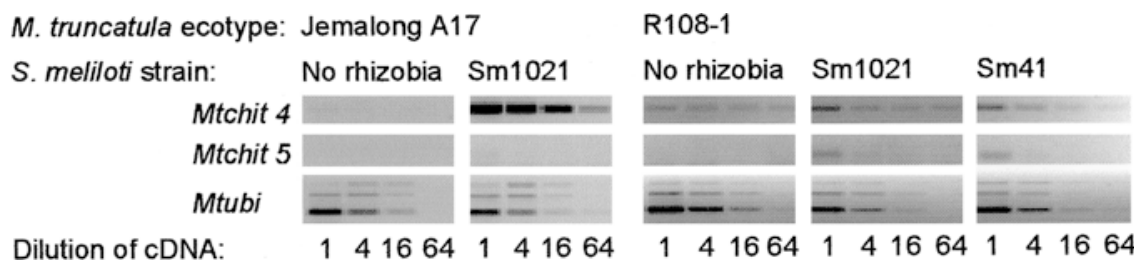
product of Mtchit 4 has a calculated molecular weight of $30,447 \mathrm{Da}$, an isoelectric point at $\mathrm{pH} 4.86$, and possesses a secretion signal peptide for apoplastic targeting.

\section{Cloning and sequencing of Mtchit 5}

From an adapter-ligated library, constructed on the basis of genomic DNA from M. truncatula R108-1, a 993-bp DraI, a 356-bp $P v u \mathrm{I}$, and a 321-bp EcoRV fragment were amplified by PCR. Sequencing of the cloned fragments showed that they could be assembled to a full-length gene sequence. With the primers Mtchit5 start-f and Mtchit5 stop-b (Table 1), we directly obtained a 1,345-bp PCR product, which contained the full-length Mtchit 5 coding region. Sequence analysis revealed an open reading frame of $1,149 \mathrm{bp}$ without introns. The ATG start codon was positioned $51 \mathrm{bp}$ downstream of the putative TATA box, CTATATACA, and $24 \mathrm{bp}$ downstream of a TAA stop codon. No polyadenylation signal was found within the $56 \mathrm{bp}$ of the cloned $3^{\prime}$ untranslated region. The Mtchit 5 sequence data are deposited at the EMBL Nucleotide Sequence Database and are accessible under AJ515476. The putative Mtchit 5 gene product is comprised of 383 amino acids, has a calculated molecular weight of $41,810 \mathrm{Da}$, and an isoelectric point at $\mathrm{pH} 7.66$.

\section{Sinorhizobium-specific induction of Mtchit 5 gene expression}

To quantify Mtchit 5 and Mtchit 4 gene expression, primers were designed that met the requirements of realtime PCR (Table 1). Transcript expression levels of Mtchit 5 and Mtchit 4 were related to the expression levels of the $M$. truncatula-specific ubiquitin gene (ubi) that served as an internal standard for plant-derived mRNA (Salzer et al. 2000). We therefore expressed the standardized transcript expression levels as Mtchit $5 / u b i$ and Mtchit $4 / u b i$ ratios.

In non-inoculated roots and leaves of $M$. truncatula R108-1, Mtchit 5/ubi ratios were very low, amounting to ca. 0.002. In flowers, Mtchit 5/ubi ratios were above the basal expression levels in roots but still in a range below 0.05 (Fig. 2a). In roots of M. truncatula R108-1 nodulated with $S$. meliloti wild-type $\mathrm{Sm} 41$, the Mtchit 5/ ubi ratios were more than 100 -fold elevated above the basic expression levels in non-nodulated roots (Fig. 2a). Specificity of Mtchit 5 induction for interactions with rhizobia became apparent by measuring its expression in other types of plant-microbe interactions. In roots colonized by the arbuscular mycorrhizal fungus Glomus intraradices, the Mtchit 5/ubi ratios remained low (Fig. 2a). In highly mycorrhized roots $(58 \%$ of the root length contained fungal structures, i.e. intraradical hyphae, arbuscules or vesicles), the Mtchit 5/ubi ratio reached a value of only 0.021 compared to 0.276 in nodulated roots. The Mtchit 5/ubi ratio remained low

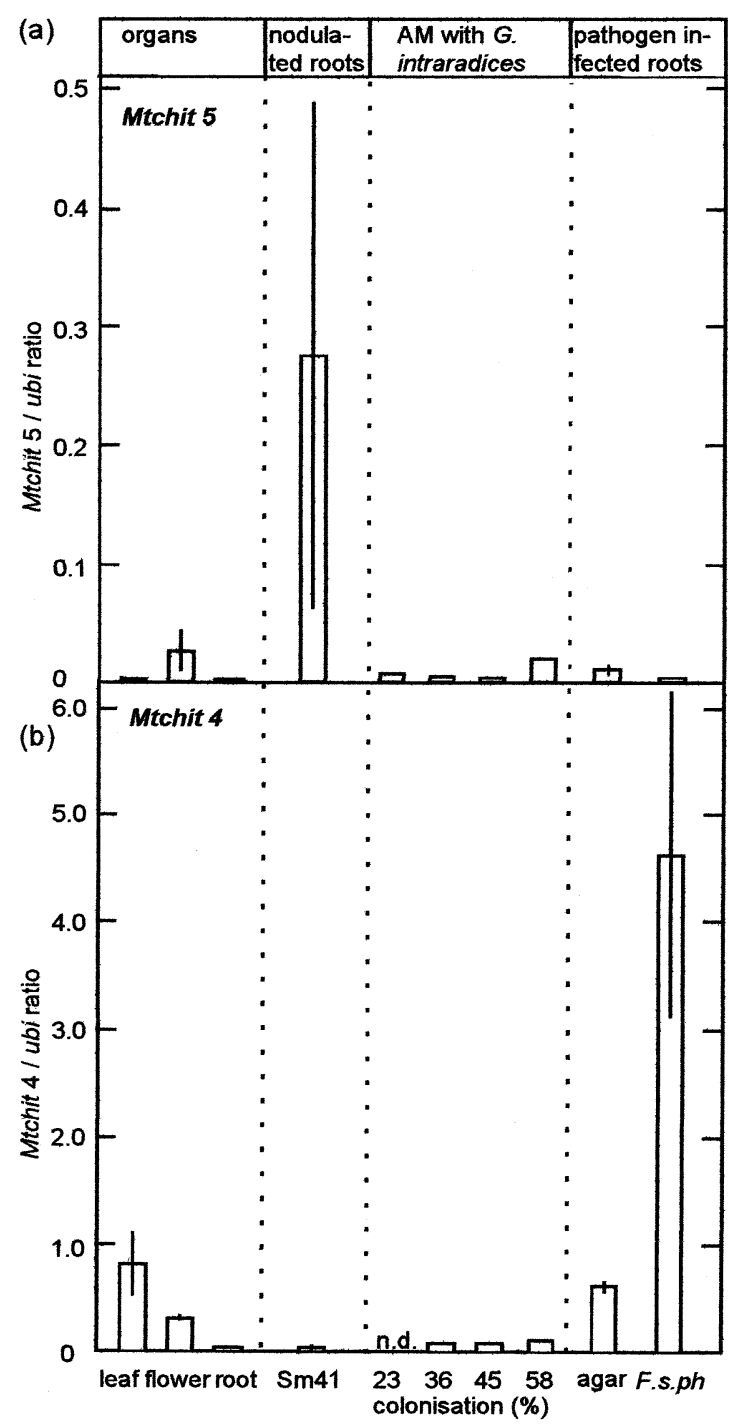

Fig. 2a, b Specific induction of Mtchit 5 in nodulated roots of M. truncatula R108-1. Expression values of Mtchit 5 (a) and Mtchit 4 (b) were determined with real-time RT-PCR. RNA was analysed from leaves (leaf), and flowers (flower), and roots (root) of 7-week-old plants, from nodulated roots inoculated with $S$. meliloti wild type strain Sm41 (Sm41), and from roots colonized with the AM fungus Glomus intraradices. The percentage of the root length containing AM fungal structures (colonization) is given for the individual plants 5 weeks post inoculation. From pathogenchallenged roots, RNA was analysed 8 days post inoculation (F.s.ph. = Fusarium solani f. sp. phaseoli; agar $=$ mock inoculation). The gene expression values of Mtchit 5 and Mtchit 4 were related to the expression values of $M$. truncatula-specific ubiquitin and are given as Mtchit 5/ubi or Mtchit 4/ubi ratios. The columns represent the mean values $( \pm S E)$ of three independent experiments, except for mycorrhizal roots, where single values of plants with a specific degree of colonization are shown. All copy numbers were measured in triplicate

also in roots challenged with the pathogenic fungus Fusarium solani $\mathrm{f}$. sp. phaseoli (Fig. 2a) that caused visible browning around the sites of inoculation.

Mtchit 4 expression levels remained low in roots of M. truncatula R108-1 plants nodulated with $S$. meliloti Sm41 (Figs. 2b, 3b), whereas inoculation of R108-1 
(a) Mtchit 5 expression (b) Mitchit 4 expression

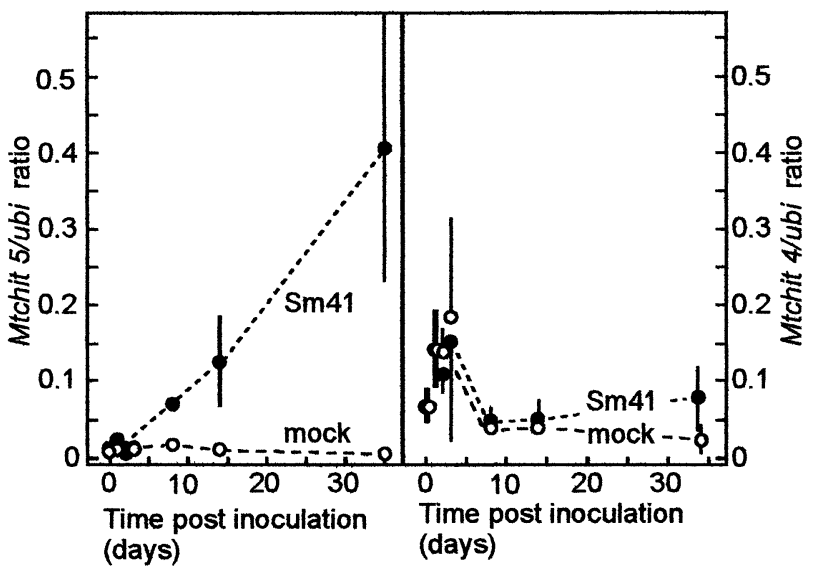

Fig. 3a, b Time-dependent increase of Mtchit 5 expression during nodule formation. Time courses of Mtchit 5 (a) and Mtchit 4 (b) expression values are depicted after inoculation with $S$. meliloti wild-type strain Sm41. M. truncatula R108-1 plants were grown on agar for 7 days, then sprayed with bacteria $(S m 41)$ or GTS medium (mock) and harvested $0,1,2$, and 3 days later. To measure later stages of the symbiosis $(8,14$, and 35 days post inoculation), 7-dayold seedlings were planted into Magenta jars and were inoculated with a bacterial suspension or GTS medium as a control. The Mtchit 5/ubi and Mtchit 4/ubi ratios were determined by real-time RT-PCR. The data shown are the means $( \pm \mathrm{SE})$ of two independent experiments with copy numbers determined in triplicate per experiment

plantlets with Fusarium solani f. sp. phaseoli resulted in elevated expression of Mtchit 4, 8 days post inoculation (Fig. 2b). Mycorrhiza formation with Glomus intraradices did not raise Mtchit 4 expression levels (Fig. 2b). Responsiveness of the $M$. truncatula $\mathrm{cv}$. R108-1 roots to AM fungal colonization was demonstrated by induction of the mycorrhiza-inducible class III chitinase gene, Mtchit 3-3 (Salzer et al. 2000). At 58\% root colonization, an Mtchit 3-3/ubi ratio of 0.2 was attained.

Mtchit 5 expression correlates with nodule development

Time-course experiments were performed to learn at which stage of nodule formation the expression of Mtchit 5 becomes elevated (Fig. 3a). Early time points (up to 3 days post inoculation) were analysed on M. truncatula cv. R108-1 seedlings that had been grown on agar plates for 7 days, and then directly sprayed with a suspension of $S$. meliloti wild-type strain $\mathrm{Sm} 41$. At these early time points, which corresponded to the stage of root hair deformation and bacterial invasion, no increased expression of Mtchit 5 was measured in roots. Later time points $(8,14$ and 35 days post inoculation) were measured in plants that had been transferred to Magenta jars and were subsequently inoculated with a rhizobial suspension. In roots of these plants (harvested 8 days post inoculation), levels of Mtchit 5 transcripts were about 4-fold higher compared to mock-inoculated control plants. At this stage of the symbiosis, the first nodule primordia started breaking through the root cortex. During the further ontogeny of the nodules, expression levels of Mtchit 5 steadily increased and reached more than 100-fold-elevated Mtchit 5/ubi ratios 5 weeks post inoculation (Fig. 3a). For comparison, Mtchit 4 expression levels were measured in the same M. truncatula plants. As shown in Fig. 3b, Mtchit 4/ubi ratios decreased over the time of the experiment, both in roots inoculated with $S$. meliloti $\mathrm{Sm} 41$ and in the mockinoculated roots.

In an additional experiment, $M$. truncatula R108-1 plants were inoculated with mutants that are unable to establish an effective symbiosis. The $S$. meliloti strain AK631lpsZ::Tn5 did not form nodules (Fig. 4a), whereas PP666h induced a number of small white nodule primordia (Fig. 4b). Plants inoculated with these strains remained small and produced purple leaves under nitrogen-limiting conditions (Fig. 4f). While Mtchit 5 expression remained at its very low basic level in roots inoculated with AK631lpsZ::Tn5, considerable increases in Mtchit 5/ubi ratios were found in roots infected with PP666h (Fig. 5a). This indicates that Mtchit 5 expression correlates with development of nodule primordia. For comparison, the expression levels were also determined for Mtchit 4. The tested strains did not induce significant differences in expression of this gene (Fig. 5b).

Differential influence of Nod factors on expression of Mtchit 5 and Mtchit 4

To study whether application of purified Nod factors elicited expression of Mtchit 5 and Mtchit 4, $1 \mathrm{ml}$ of the tetrameric Nod factor, $\operatorname{NodSm}-\operatorname{IV}\left(\mathrm{C}_{16: 2}, \mathrm{~S}\right)$, was sprayed on roots at a concentration of $0.5 \mu \mathrm{M}$. Control plants were mock-treated with water. Within $48 \mathrm{~h}$, Mtchit 5/ubi ratios were significantly elevated in the Nod factor-treated compared to water-treated roots (Fig. 6a). Mtchit 4 expression, in contrast, steadily decreased, both in Nod factor-treated and water-treated control roots (Fig. 6b).

Differential influence of $\mathrm{K}$ antigen on expression of Mtchit 5 and Mtchit 4

A possible effect of $\mathrm{K}$ antigen on chitinase gene expression was investigated by a mutant-based approach. R108-1 plants were inoculated either with S. meliloti Sm41 or its mutant PP699 (Putnoky et al. 1990). PP699 is mutated in the rkp-1 region and thus deficient in K antigen synthesis (Petrovics et al. 1993; Kiss et al. 1997). Plants inoculated with PP699 formed pink nitrogen-fixing $\left(\mathrm{fix}^{+}\right)$nodules (Fig. $\left.4 \mathrm{~d}\right)$ that promoted plant growth under nitrogen-limiting conditions (Fig. 4f). Roots infected with the parent $S$. meliloti strain Sm41 (Fig. 4c) developed nodules slightly faster than PP699, suggesting a symbiosis-promoting effect of 
Roots infected with:

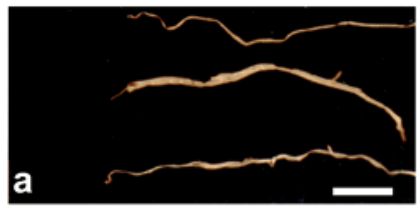

AK631 IpsZ::Tn5

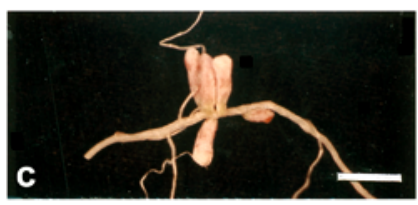

Sm41

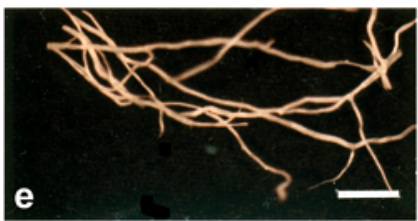

no Sm

\section{Plants cultured with:}

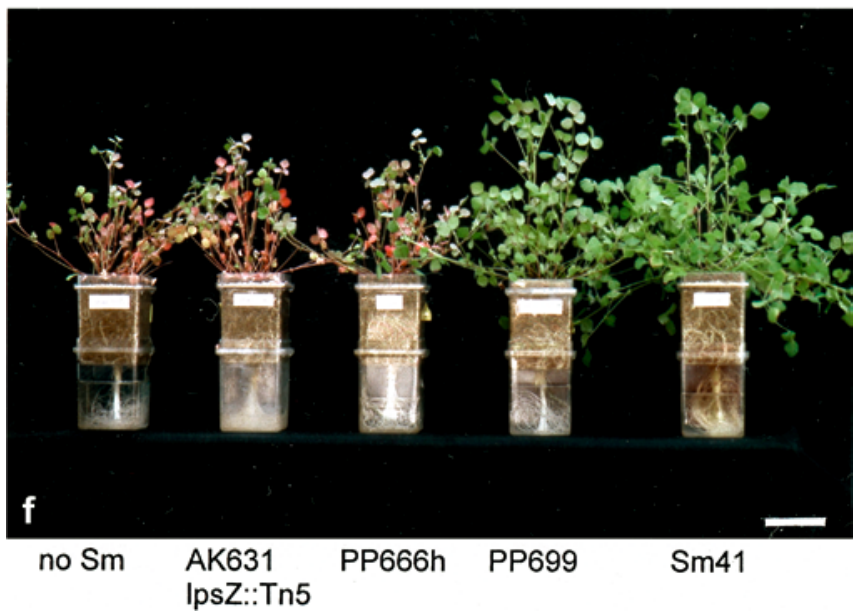

Fig. 4a-f Symbiotic interactions between $M$. truncatula R108-1 and different $S$. meliloti mutants (5 weeks post inoculation). a Roots inoculated with AK631lpsZ::Tn5. b Roots inoculated with PP666h. White arrowheads indicate nodule primordia that did not develop to nodules. c Roots nodulated with Sm41. d Nodules induced by PP699 (Sm41 mutated in the rkp-1 region). e Noninoculated roots of plants germinated at the same time as the inoculated ones (no Sm). f Phenotype of plants at the time of harvest. A plant growth-promoting effect is seen for the effective symbioses with PP699 and Sm41. Bars $=1 \mathrm{~cm}(\mathbf{a}-\mathbf{e}), 5 \mathrm{~cm}(\mathbf{f})$

$\mathrm{K}$ antigen in this interaction. Compared to mock-inoculated roots, Mtchit 5/ubi ratios (5 weeks post inoculation) were more than 100-fold increased in roots nodulated with either Sm41 or PP699. The degree of Mtchit 5 induction did not show any significant difference between the two strains (Fig. 7a). The Mtchit 4 gene, in contrast, showed a different induction profile between Sm41 and PP699. Compared to S. meliloti wild type strain Sm41, roots infected with the K-antigendeficient mutant PP699 exhibited on average 4.5-fold higher Mtchit 4/ubi ratios (Fig. 7b).

\section{(a) Mtchit 5 expression (b) Mtchit 4 expression}

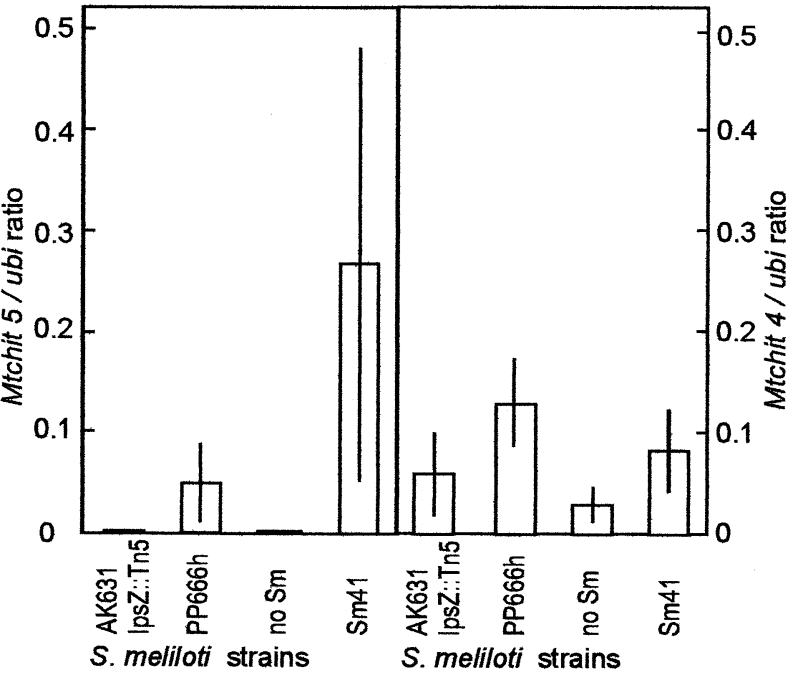

Fig. 5a, b Expression of chitinases in M. truncatula R108-1 roots during ineffective symbioses. Plants were inoculated with $S$. meliloti AK631lpsZ::Tn5, PP666h or for comparison with Sm41 wild type. Five weeks later, Mtchit 5 (a) and Mtchit 4 (b) expression levels were determined by real-time RT-PCR. Chitinase gene expression levels are shown as Mtchit 5/ubi or Mtchit 4/ubi ratios. Elevated Mtchit 5/ubi ratios were found in roots with ineffective nodule primordia induced by PP666h as well as in plants forming effective nodules with Sm41. Data indicate means $( \pm \mathrm{SE})$ of three independent experimental series

\section{(a) Mtchit 5 expression (b) Mtchit 4 expression}

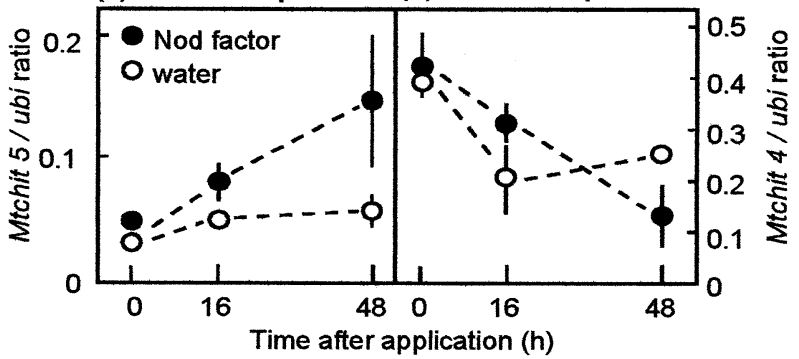

Fig. 6a, b Effect of Nod factors on gene expression of Mtchit 5 and Mtchit 4. Roots of 1-week-old M. truncatula R108-1 plantlets were sprayed with $1 \mathrm{ml} 0.5 \mu \mathrm{M} \operatorname{NodSm-IV}\left(\mathrm{C}_{16: 2}, \mathrm{~S}\right)$ or water. Mtchit 5 (a) and Mtchit 4 (b) expression levels were measured after indicated time points by real-time RT-PCR. The chitinase expression levels are given as Mtchit/ubi ratios. Data shown are means $( \pm \mathrm{SE})$ of two independent experimental series with expression values determined in triplicate

Putative properties of the deduced Mtchit 5 polypeptide

The HmmerPfam analysis of the deduced amino acid sequence revealed that the putative Mtchit 5 gene product belongs to glycosyl hydrolase family 18 . The two consensus motifs of class $\mathrm{V}$ chitinases, box 1 within the substrate-binding cleft, and box 2 within the catalytic centre contained the enzymatically active Asp (D) and Glu (E), respectively (Watanabe et al. 1993; Kim et al. 2002; Fig. 8). This suggests that the putative Mtchit 5 protein is an enzymatically active class $\mathrm{V}$ 
$\begin{array}{lll}\text { (a) Mtchit } 5 \text { expression } & \text { (b) Mtchit } 4 \text { expression }\end{array}$

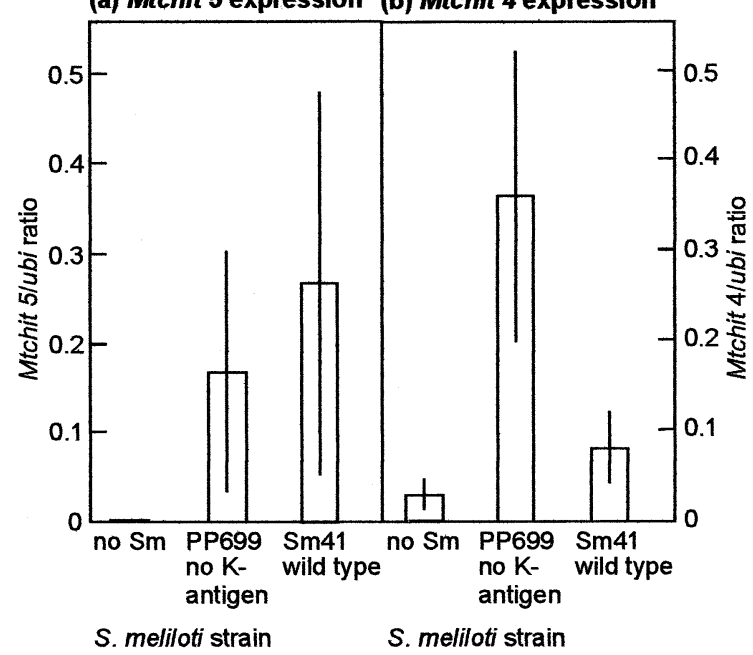

Fig. 7a, b Expression of Mtchit 5 and Mtchit 4 in the interaction between $M$. truncatula R108-1 and S. meliloti PP699, a K-antigendeficient mutant of Sm41. Plants were inoculated with Sm41 and PP699, which is mutated in the $r k p-1$ region. Control plants were inoculated with GTS medium (no Sm). Five weeks later, nodulated roots were harvested and Mtchit 5 (a) and Mtchit 4 (b) expression levels were measured with real-time RT-PCR. Columns show mean values $( \pm \mathrm{SE})$ of Mtchit $5 / u b i$ and Mtchit 4/ubi ratios from three independent experiments with copy numbers measured in triplicate per experiment

chitinase. The localization of the mature protein could not be clearly predicted. PSORT predicted cleavage of a signal peptide at position 26, while SPScan revealed no presence of a secretory signal peptide.

\section{Phylogenetic analysis of class V and IV chitinases}

For phylogenetic analysis, BLASTP searches in the EMBL, PIR and SwissProt databases against the putative Mtchit 5 and Mtchit 4 gene products were performed. In the case of Mtchit 5, the 24 top-scored matches of class $\mathrm{V}$ chitinases, in the case of Mtchit 4 the 19 top-scored matches with class IV chitinases were selected. The entire amino acid sequences were used for the construction of unrooted phylogenetic trees. As expected, there was a large phylogenetic distance between the class IV and the class V chitinases. Within the class V chitinases, the putative Mtchit 5 gene product formed an individual clade that was distant from other class $\mathrm{V}$ chitinases of plants, animals and Homo sapiens (Fig. 9a). Within the phylogenetic tree, class V chitinases from Nicotiana tabacum grouped together with chitinases and further members of the glycosyl hydrolase family 18 of Arabidopsis thaliana. The deduced Mtchit 5 gene product had the highest similarities to the $A$. thaliana chitinase homolog $\mathrm{T} 16 \mathrm{H} 5.170$ (53\% similarity, $36 \%$ identity), to the tobacco pz chitinase (52\% similarity, 33\% identity; Heitz et al. 1994) and to the tobacco Chi-V (52\% similarity, 33\% identity; Melchers et al. 1994).
The putative Mtchit 4 gene product was closely related to other class IV chitinases from legumes. The chitinases most related to Mtchit 4 were either pathogen induced or expressed in nodulated roots. As with the class $\mathrm{V}$ chitinases, the class IV chitinases exhibited a strict species-related grouping (Fig. 9b). The Mtchit 4 gene product has the highest similarities to the endochitinase PR4 precursor of Phaseolus vulgaris $(82 \%$ similarity, 75\% identity; Lange et al. 1996; accession number: P27054), the class IV chitinase of Galega orientalis ( $81 \%$ similarity, $73 \%$ identity; accession number: AAP03085) and the class IV chitinase of Vigna unguiculata (79\% similarity, $71 \%$ identity; accession number: CAA61281).

\section{Discussion}

Ecotype-specific variation in nodule formation is known from natural M. truncatula populations. For example, the Algerian M. truncatula cultivar DZA315.16 is able to form nitrogen-fixing nodules with the $S$. meliloti strain A145, whereas the Australian cultivar Jemalong 6 formed only small ineffective nodules with this strain (Tirichine et al. 2000). In our studies, comparison of chitinase gene expression in nodulated roots revealed a qualitative difference between the $M$. truncatula ecotypes R108-1 and Jemalong A17. Nodule formation with $S$. meliloti 1021 resulted in transcript accumulation of Mtchit 4 in Jemalong A17, whereas expression of this chitinase gene was not elevated above its basic expression level in R108-1 (Fig. 1). In contrast to Mtchit 4, expression of Mtchit 5 was induced in both ecotypes. Compared to R108-1, expression in Jemalong A17 was rather low, however (Fig. 1). A quantitative difference in chitinase gene expression was also found for Mtchit 3-3, a chitinase gene of $M$. truncatula that is specifically induced in response to AM formation (Salzer et al. 2000). AM-induced transcript levels of Mtchit 3-3 were about 5-fold lower in R108-1 than in Jemalong A17 (our unpublished data).

We consider Mtchit 4 to be a chitinase gene that is related to a general plant defence response for the following reasons: (i) The gene was induced upon infection with the pathogenic fungus Fusarium solani f. sp. phaseoli in M. truncatula R108-1 (Fig. 2) and Jemalong A17 (Salzer et al. 2000). (ii) Mtchit 4 is closely related to pathogen- and elicitor-induced class IV chitinases of legumes, wine, and the non-symbiotic Arabidopsis (Fig. 9). (iii) Mtchit 4 was not induced by rhizobial Nod factors (Fig. 6b) or by symbiotic AM fungi (Fig. 2b). Considering Mtchit 4 induction as a part of a general defence response, low transcript levels in the interaction between M. truncatula R108-1 and S. meliloti Sm41 would indicate an optimal compatibility between the two symbiotic partners. In this view, enhanced accumulation of Mtchit 4 transcripts induced by the K-antigen-deficient mutant PP699 is remarkable. We suggest therefore that $\mathrm{K}$ antigens are involved in 
Fig. 8 Alignment of plant class V chitinases. Deduced amino acid sequences of chitinases from $M$. truncatula (M. tru.), Arabidopsis thaliana (A. tha.), Nicotiana tabacum, Momordica charantia (bitter melon), and Oryza sativa were aligned. Amino acid residues identical to the consensus sequence are labelled in black. The consensus sequence for plant class $\mathrm{V}$ chitinases (consensus) was established under the criterion of $67 \%$ amino acid identity per residue. Putative secretion signal peptides are typed in italics. The conserved regions of the substrate binding cleft, Box 1, and the catalytic centre, Box 2 , are underlined. The enzymatically essential amino acids $\mathrm{D}$ and $\mathrm{E}$ are indicated by stars (*). Gaps that have been introduced to fit the alignment are indicated by hyphens (-)
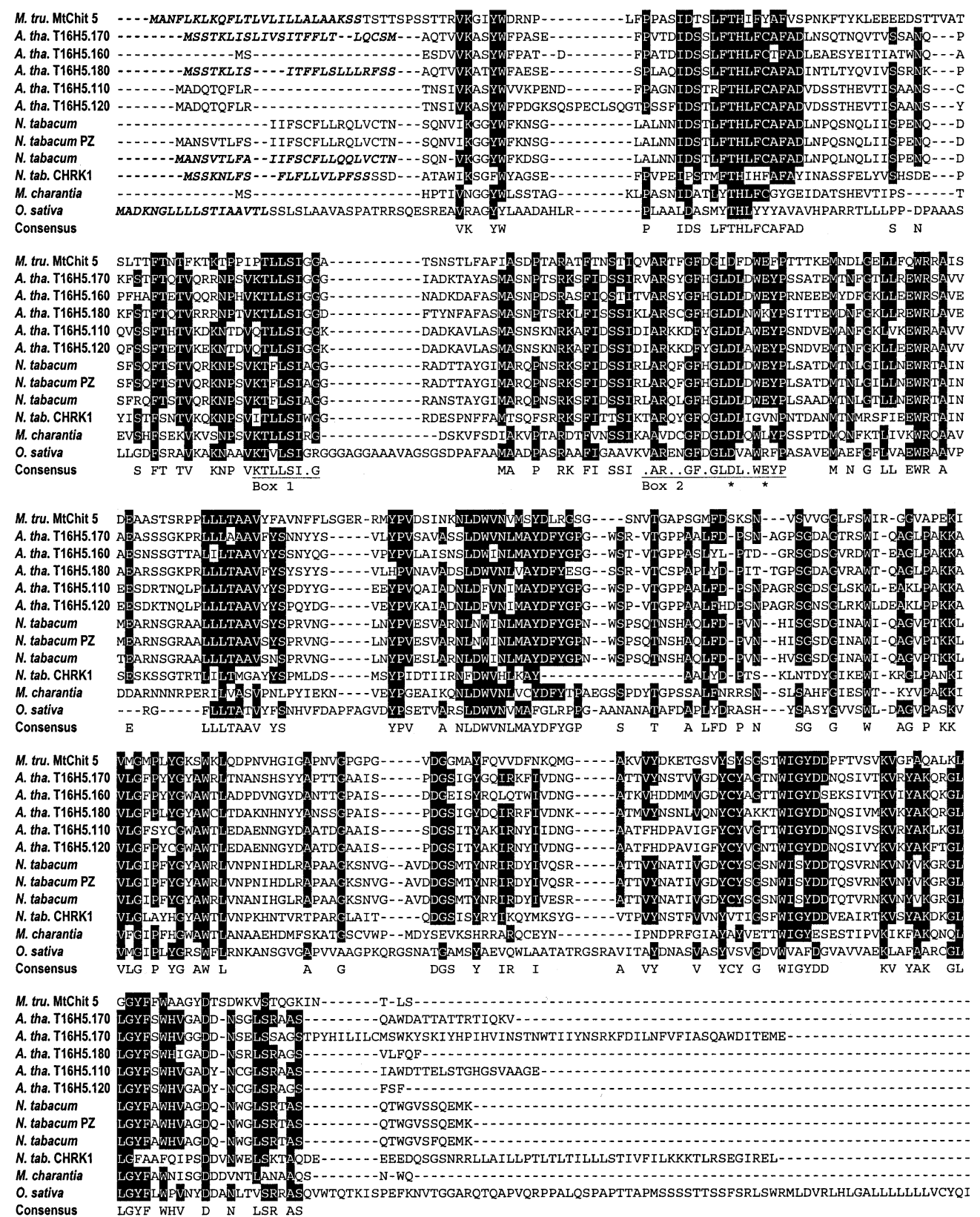

suppression of plant defence reactions directed against the invading bacteria. This is reminiscent of the proposed function of other surface polysaccharides (Mithöfer 2002). Future work is required to demonstrate a direct link between $\mathrm{K}$ antigen and suppression of inducible plant defence reactions.

Real-time RT-PCR enabled us to quantitatively analyze Mtchit 5 expression, even though transcripts accumulated only at low abundance. Using this approach, we found that transcription of Mtchit 5 is specifically induced in the symbiosis with $S$. meliloti. Fungal pathogens and mycorrhizal fungi did not induce Mtchit 5 in roots of R108-1 (Fig. 2a). Thus, Mtchit 5 can be considered as a putative chitinase gene that is specific for nodules in M. truncatula ecotype R108-1.
Mtchit 5 belongs to the class $\mathrm{V}$ chitinases and forms a separate clade within the phylogenetic tree of class $\mathrm{V}$ chitinases of plants and animals (Fig. 9). Mtchit 3-3, which is specifically expressed in mycorrhizal roots of both M. truncatula ecotypes (Salzer et al. 2000; Bonanomi et al. 2001; this work), belongs to the class III chitinases and is structurally different from class $\mathrm{V}$ chitinases. This indicates that M. truncatula evolved two types of chitinase, which are independently activated in response to nodule formation and mycorrhiza formation. In the tripartite symbiosis with $S$. meliloti and AM fungi, expression of both genes is induced (data not shown).

Mtchit 5 expression had already occurred early during nodule development. Although this gene is also 
(a) Chitinases class $\mathrm{V}$

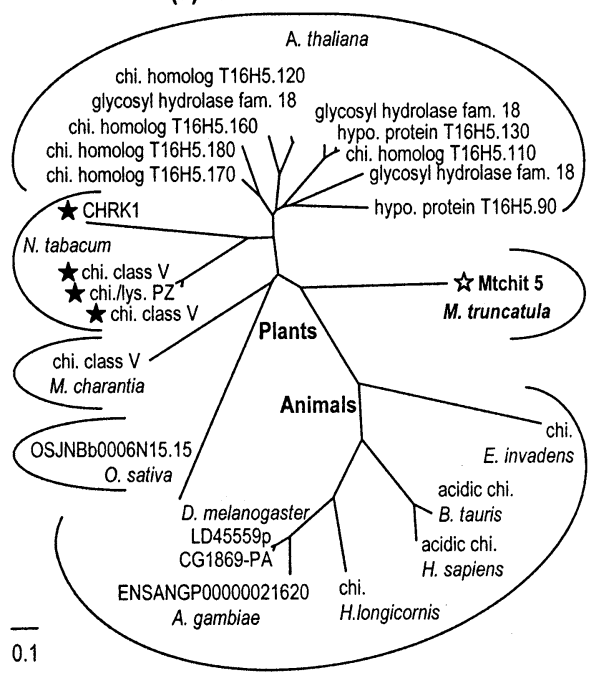

Fig. 9a, b Unrooted phylogenetic trees of class V (a) and class IV (b) chitinases. A BLASTP search was performed with the fulllength amino acid sequences of the putative Mtchit 5 and Mtchit 4 gene products. Twenty-four class $\mathrm{V}$ amino acid sequences were obtained with a bit score $>125$, and were used to construct a phylogenetic tree. These sequences originate from plants (M. truncatula, Arabidopsis thaliana, Nicotiana tabacum, Oryza sativa, Momordica charantia), insects (Drosophila melanogaster, Anopheles gambiae), mammals (Bos taurus, Homo sapiens), the tick Haemaphysalis longicornis, and the protist Entamoeba invadens. In the case of class IV chitinases, 20 amino acid sequences with a bit score $>300$ were obtained. The sequences stem from rice (Oryza sativa), wine (Vitis vinifera), sugar beet (Beta vulgaris), pigweed (Chenopodium amaranticolor), carrot (Daucus carota), thale cress (Arabidopsis thaliana), cowpea (Vigna unguiculata), common bean (Phaseolus vulgaris), and goat's rue (Galega orientalis). Black stars indicate chitinases that are pathogen induced; white stars indicate chitinases that are Sinorhizobium induced. No information was available about induction of chitinases without labelling. The bars give 0.1 amino acid exchanges per residue. Note the different scales applied for class $\mathrm{V}$ and class IV chitinases

expressed in flowers, we consider Mtchit 5 as an early nodulin-like gene. This is reminiscent of the Srchil3 chitinase gene from Sesbania rostrata, whose transcripts transiently accumulated during nodule formation (Goormachtig et al. 1998). Mtchit 5 and Srchil3 are members of the glycosyl hydrolase family 18 (Henrissat et al. 1991), but they do not belong to the same class of chitinases. The Srchil3 gene codes for a class III chitinase, whereas Mtchit 5 codes for a putative class $\mathrm{V}$ chitinase.

In contrast to Mtchit 4, Mtchit 5 seems not to be part of a plant defence reaction. There are several arguments in favour of this assumption: (i) The Mtchit 5 gene is activated during nodulation, but not when roots are challenged with a fungal pathogen. (ii) Mtchit 5 is expressed in low abundance. This is not typical of defence-related genes, which are usually strongly induced. (iii) In response to Nod factors, transcripts of Mtchit 5 accumulated to levels that are far above those induced after inoculation with $S$. meliloti $\mathrm{Sm} 41$ at the same time (compare Figs. 3a and 6a). (iv) Expression

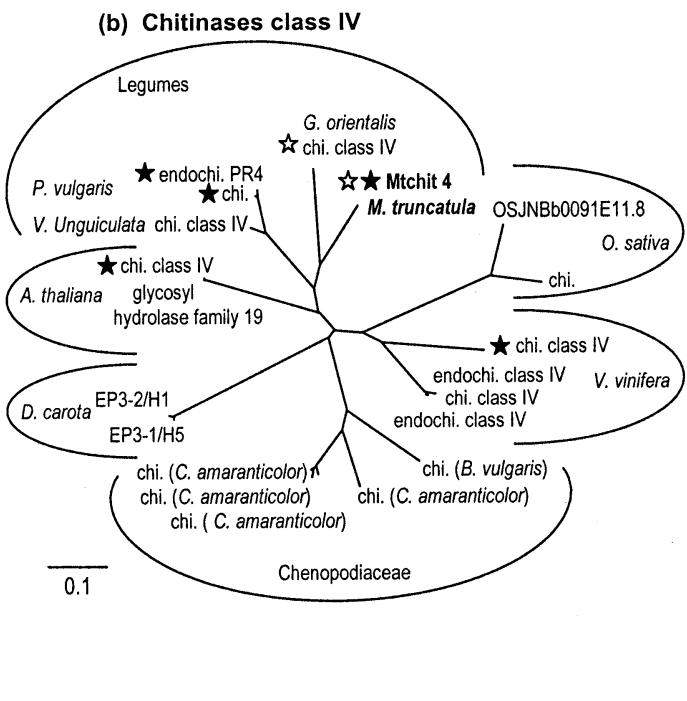

patterns of Mtchit 5 differed from those of the defencerelated Mtchit 4 (e.g. see Fig. 7).

In fact, we can only speculate about the function of Mtchit 5. Its symbiosis-specific induction and its responsiveness to Nod factors suggest a function during establishment of the nodule symbiosis. A role of chitinases in developmental processes is known from somatic embryo formation of carrot cells (de Jong et al. 1992). Recent findings indicate that $N$-acetylglucosamine-containing arabinogalactan proteins of carrot cells are sensitive to chitinase cleavage and that the chitinase-modified proteins reinitiate cell division of non-dividing protoplasts (van Hengel et al. 2001). Although functionality and subcellular localization of the putative Mtchit 5 chitinase have not been studied experimentally, it is tempting to speculate that Mtchit 5 could modify arabinogalactan proteins in the dividing cells of the nodule meristem. Targets of Mtchit 5 enzymatic activity might be early nodulins, such as PsENOD5 (Scheres et al. 1990), MtENOD16 and MtENOD20 (Greene et al. 1998), which are predicted to be possibly $O$-glycosylated with arabinogalactans.

In conclusion, this comparative study on expression of two $M$. truncatula chitinases opens a first insight into the differences between regulation of symbiosis-specific and pathogen-related chitinase genes during nodule formation and in response to rhizobial signal molecules. The identification of Mtchit 5 as an early nodulin-like gene, suggests a function that is different from plant defence. Future in situ mRNA hybridization and antibody-based localization studies as well as the analysis of the enzymatic properties of the purified Mtchit 5 proteins are required to better understand the role of this chitinase during nodulation.

Acknowledgements We are grateful to Peter Putnoky (University of Pécs, Pécs, Hungary) and Eva Kondorosi (Institut des Sciences du Végétal, CNRS, Gif-sur-Yvette, France) for providing bacterial strains. We also thank our colleagues from the Botanical Institute in Basel, Dirk Redecker, Philipp Raab, and Virgine Galati, for their help in phylogenetic analysis and for technical assistance. 


\section{References}

Albus U, Baier R, Holst O, Pühler A, Niehaus K (2001) Suppression of an elicitor-induced oxidative burst reaction in Medicago sativa cell cultures by Sinorhizobium meliloti lipopolysaccharides. New Phytol 151:597-606

Bécard G, Fortin FA (1988) Early events of vesicular-arbuscular mycorrhiza formation on Ri T-DNA transformed roots. New Phytol 108:211-218

Blondon F, Marie D, Brown S, Kondorosi A (1994) Genome size and base composition in Medicago sativa and Medicago truncatula species. Genome 37:264-270

Bonanomi A, Wiemken A, Boller T, Salzer P (2001) Local induction of a mycorrhiza-specific class III chitinase gene in cortical root cells of Medicago truncatula containing developing or mature arbuscules. Plant Biol 3:194-199

Broglie K, Chet I, Holliday M, Cressman R, Biddle P, Knowlton S, Mauvais CJ, Broglie R (1991) Transgenic plants with enhanced resistance to the fungal pathogen Rhizoctonia solani. Science 254:1194-1197

Broughton WJ, John CK (1979) Rhizobia in tropical legumes. III. Experimentation and supply in Malaysia 1927-1976. In: Broughton WJ, John CK, Lim B, Rajova C (eds) Soil microbiology and plant nutrition. University of Malaysia, Kuala Lumpur, pp 113-136

Brunner F, Stintzi A, Fritig B, Legrand M (1998) Substrate specificities of tobacco chitinases. Plant J 14:225-234

Charon C, Sousa C, Crespi M, Kondorosi A (1999) Alteration of enod40 expression modifies Medicago truncatula root nodule development induced by Sinorhizobium meliloti. Plant Cell 11:1953-1965

Cook D, van den Bosch K, de Bruijn F, Huguet T (1997) Model legumes get the nod. Plant Cell 9:275-281

de Jong AJ, Cordewener J, Lo Schiavo F, Terzi M, Vandekerckhove J, van Kammen A, de Vries SC (1992) A carrot somatic embryo mutant is rescued by chitinase. Plant Cell $4: 425-433$

Gamas P, de Billy F, Truchet G (1998) Symbiosis-specific expression of two Medicago truncatula nodulin genes, MtNI and $M t N 13$, encoding products homologous to plant defense proteins. Mol Plant Microbe Interact 11:393-403

Giovanetti M, Mosse B (1980) An evaluation of techniques for measuring vesicular arbuscular infection in roots. New Phytol $84: 489-500$

Goormachtig S, Lievens S, van de Velde W, van Montagu M, Holsters M (1998) Srchi13, a novel early nodulin from Sesbania rostrata, is related to acidic class III chitinases. Plant Cell 10:905-915

Goormachtig S, van de Velde W, Lievens S, Verplancke C, Herman S, de Keyser A, Holsters M (2001) Srchi24, a chitinase homolog lacking an essential glutamic acid residue for hydrolytic activity, is induced during nodule development on Sesbania rostrata. Plant Physiol 127:78-89

Greene EA, Erard M, Dedieu A, Barker DG (1998) MtENOD16 and 20 are members of a family of phytocyanin-related early nodulins. Plant Mol Biol 36:775-783

Hamel F, Boivin R, Tremblay C, Bellemare G (1997) Structural and evolutionary relationships among chitinases of flowering plants. J Mol Evol 44:614-624

Heidstra R, Geurts R, Franssen H, Spaink HP, van Kammen A, Bisseling T (1994) Root hair deformation activity of nodulation factors and their fate on Vicia sativa. Plant Physiol 105:787-797

Heitz T, Segond S, Kauffmann S, Geoffroy P, Prasad V, Brunner F, Fritig B, Legrand M (1994) Molecular characterization of a novel tobacco pathogenesis-related (PR) protein: a new plant chitinase/lysozyme. Mol Gen Genet 245:246-254

Henrissat B (1991) A classification of glycosyl hydrolases based on amino acid sequence similarities. Biochem J 280:309-316

Hirsch AM, Kapulnik Y (1998) Signal transduction pathways in mycorrhizal associations: comparisons with the Rhizobium-legume symbiosis. Fung Gen Biol 23:205-212
Hoffmann B, Trinh TH, Leung J, Kondorosi A, Kondorosi E (1997) A new Medicago truncatula line with superior in vitro regeneration, transformation, and symbiotic properties isolated through cell culture selection. Mol Plant Microbe Interact 10:307-315

Kannenberg EL, Reuhs BL, Forsberg LS, Carlson RW (1998) Lipopolysaccharides and $\mathrm{K}$ antigens: their structures, biosynthesis, and functions. In: Spaink HP, Kondorosi A, Hooykaas PJJ (eds) The Rhizobiaceae. Kluwer, Dordrecht, pp 119-154

Kim YS, Lee JH, Yoon GM, Cho HS, Park SW, Suh MC, Choi D, Ha HJ, Liu JR, Pai HS (2000) CHRK1, a chitinase-related receptor-like kinase in tobacco. Plant Physiol 123:905-915

Kim DJ, Baek JM, Uribe P, Kenerley CM, Cook DR (2002) Cloning and characterization of multiple glycosyl hydrolase genes from Trichoderma virens. Curr Genet 40:374-384

Kiss GB, Vincze E, Kalman Z, Forrai T, Kondorosi A (1979) Genetic and biochemical analysis of mutants affected in nitrate reduction in Rhizobium meliloti. J Gen Microbiol 113:105-118

Kiss E, Reuhs BL, Kim JS, Kereszt A, Petrovics G, Putnoky P, Dusha I, Carlson RW, Kondorosi A (1997) The rkpGHI and -J genes are involved in capsular polysaccharide production by Rhizobium meliloti. J Bacteriol 179:2132-2140

Lange J, Mohr U, Wiemken A, Boller T, Vögeli-Lange R (1996) Proteolytic processing of class IV chitinase in the compatible interaction of bean roots with Fusarium solani. Plant Physiol 111:1135-1144

Mauch F, Mauch-Mani B, Boller T (1988) Antifungal hydrolases in pea tissue. II. Inhibition of fungal growth by combinations of chitinase and $\beta$-1,3-glucanase. Plant Physiol 88:936-942

Melchers LS, Apotheker-de Groot M, van der Knaap JA, Ponstein AS, Sela-Buurlage MS, Bol JF, Cornelissen BJC, van den Elzen PJM, Linthorst HJM (1994) A new class of tobacco chitinases homologous to bacterial exo-chitinases displays antifungal activity. Plant J 5:469-480

Mithöfer A (2002) Suppression of plant defence in rhizobia-legume symbiosis. Trends Plant Sci 7:440-444

Neuhaus JM, Fritig B, Linthorst HJM, Meins F, Mikkelsen JD, Ryals JA (1996) A revised nomenclature for chitinase genes. Plant Mol Biol Rep 14:102-104

Niehaus K, Kapp D, Pühler A (1993) Plant defence and delayed infection of alfalfa pseudonodules induced by an exopolysaccharide (EPS I)-deficient Rhizobium meliloti mutant. Planta 190:415-425

Pellock BJ, Cheng HP, Walker GC (2000) Alfalfa root nodule invasion efficiency is dependent on Sinorhizobium meliloti polysaccharides. J Bacteriol 182:4310-4318

Perlick AM, Frühling M, Schröder G, Frosch SC, Pühler A (1996) The broad bean gene VfNOD32 encodes a nodulin with sequence similarities to chitinases that is homologous to $(\alpha / \beta)$ barrel-type seed proteins. Plant Physiol 110:147-154

Perret X, Staehelin C, Broughton WJ (2000) Molecular basis of symbiotic promiscuity. Microbiol Mol Biol Rev 64:180-201

Petrovics G, Putnoky P, Reuhs B, Kim J, Thorp TA, Noel KD, Carlson RW, Kondorosi A (1993) The presence of a novel type of surface polysaccharide in Rhizobium meliloti requires a new fatty acid synthase-like gene cluster involved in symbiotic nodule development. Mol Microbiol 8:1083-1094

Putnoky P, Petrovics G, Kereszt A, Grosskopf E, Ha DT, Banfalvi Z, Kondorosi A (1990) Rhizobium meliloti lipopolysaccharide and exopolysaccharide can have the same function in the plantbacterium interaction. J Bacteriol 172:5450-5458

Reuhs BL, Carlson RW, Kim JS (1993) Rhizobium fredii and Rhizobium meliloti produce 3-deoxy-D-manno-2-octulosonic acid-containing polysaccharides that are structurally analogous to group II $\mathrm{K}$ antigens (capsular polysaccharides) found in Escherichia coli. J Bacteriol 175:3570-3580

Reuhs BL, Williams MNV, Kim JS, Carlson RW, Coté F (1995) Suppression of the $\mathrm{fix}^{-}$phenotype of Rhizobium meliloti exoB mutants by $\operatorname{lps} Z$ is correlated to a modified expression of the K polysaccharide. J Bacteriol 177:4289-4296

Salzer P, Bonanomi A, Beyer K, Vögeli R, Aeschbacher RA, Lange J, Wiemken A, Kim D, Cook DR, Boller T (2000) Differential expression of eight chitinase genes in Medicago truncatula roots 
during mycorrhiza formation, nodulation and pathogen infection. Mol Plant Microbe Interact 13:763-777

Sambrook J, Fritsch EF, Maniatis T (1989) Molecular cloning. Cold Spring Harbor Laboratory Press, Cold Spring Harbor, NY

Scheres B, van Engelen F, van der Knaap E, van de Wiel C, van Kammen A, Bisseling T (1990) Sequential induction of nodulin gene expression in the developing pea nodule. Plant Cell 2:687700

Schultze M, Quiclet-Sire B, Kondorosi E, Virelizier H, Glushka JN, Endre G, Géro SD, Kondorosi A (1992) Rhizobium meliloti produces a family of sulfated lipooligosaccharides exhibiting different degrees of plant host specificity. Proc Natl Acad Sci USA 89:192-196

Staehelin C, Müller J, Mellor RB, Wiemken A, Boller T (1992) Chitinase and peroxidase in effective $\left(\mathrm{fix}^{+}\right)$and ineffective (fix $\left.{ }^{-}\right)$ soybean nodules. Planta 187:295-300

Staehelin C, Schultze M, Kondorosi E, Mellor RB, Boller T, Kondorosi A (1994) Structural modifications in Rhizobium meliloti Nod factors influence their stability against hydrolysis by root chitinases. Plant $\mathbf{J}$ 5:319-330

Staehelin C, Schultze M, Kondorosi E, Kondorosi A (1995) Lipochitooligosaccharide nodulation signals from Rhizobium meliloti induce their rapid degradation by the host plant alfalfa. Plant Physiol 108:1607-1614

Staehelin C, Schultze M, Tokuyasu K, Poinsot V, Promé JC, Kondorosi E, Kondorosi A (2000) $\mathrm{N}$-deacetylation of Sinorhizobium meliloti Nod factors increases their stability in the Medicago sativa rhizosphere and decreases their biological activity. Mol Plant Microbe Interact 13:72-79

Staehelin C, Charon C, Crespi M, Boller T, Kondorosi A (2001) Medicago truncatula plants overexpressing the early nodulin gene enod40 exhibit accelerated mycorrhizal colonization and enhanced formation of arbuscules. Proc Natl Acad Sci USA 98:15366-15371
Tirichine L, de Billy F, Huguet T (2000) Mtsym6, a gene conditioning Sinorhizobium strain-specific nitrogen fixation in Medicago truncatula. Plant Physiol 123:845-851

van den Bosch KA, Stacey G (2003) Summaries of legume genomics projects from around the globe. Community resources for crops and models. Plant Physiol 131:840-865

van Hengel AJ, Tadesse Z, Immerzeel P, Schols $\mathrm{H}$, van Kammen A, de Vries SC (2001) $N$-acetylglucosamine and glucosaminecontaining arabinogalactan proteins control somatic embryogenesis. Plant Physiol 125:1880-1890

Vasse J, de Billy F, Truchet G (1993) Abortion of infection during the Rhizobium meliloti-alfalfa symbiotic interaction is accompanied by a hypersensitive reaction. Plant J 4:555-566

Watanabe T, Kobori K, Miyashita K, Fuji T, Sakai H, Uchida M, Tanaka H (1993) Identification of glutamic acid 204 and aspartic acid 200 in chitinase A1 from Bacillus circulans WL-12 as essential residues for chitinase activity. J Biol Chem 268:18567-18572

Wiweger M, Farbos I, Ingouff M, Lagercrantz U, von Arnold S (2003) Expression of Chia4-Pa chitinase genes during somatic and zygotic embryo development in Norway spruce (Picea abies): similarities and differences between gymnosperm and angiosperm class IV chitinases. J Exp Bot 54:2691-2699

Wyss P, Mellor RB, Wiemken A (1990) Vesicular-arbuscular mycorrhizas of wild type soybean and non-nodulating mutants with Glomus mosseae contain symbiosis-specific polypeptides (mycorrhizins) immunologically cross-reactive with nodulins. Planta 182:22-26

Xie ZP, Staehelin C, Wiemken A, Broughton WJ, Müller J, Boller $\mathrm{T}$ (1999) Symbiosis-stimulated chitinase isoenzymes of soybean (Glycine max (L.) Merr.). J Exp Bot 50:327-333 